\title{
Synthesis, characterization and properties of polymers containing simultaneously the imine and amide moieties.
}

\author{
Christian Sánchez, ${ }^{1 *}$ Carlos Bustos, ${ }^{1}$ Fabiola Alvarado, ${ }^{1}$ Eduardo Schott, ${ }^{1}$ Nicolas \\ Gatica, ${ }^{2}$ Jean-Christian Bernede ${ }^{3}$
}

${ }^{1}$ Instituto de Química, Universidad Austral de Chile, Avda. Los Robles s/n, Campus Isla Teja, Casilla 567, Valdivia, Chile. Fax: 56-63-221597. christiansanchez@uach.cl

${ }^{2}$ Departamento de Polímeros, Facultad de Química, Universidad de Concepción, Avda. Edmundo Larenas 129, Concepción, Chile. Fax: 56-41-245974. nigatica@udec.cl

${ }_{3}$ Laboratoire de Matériaux Photovoltaiques, Faculté de Sciences, Université de Nantes, BP 92208, 2, Rue de la Houssinière 44322, Nantes Cedex 3, France. Fax: 33-2-51125528. jean-christian.bernede@univ-nantes.fr

(Received: 2 December, 2006; published: 9 April 2007)

\begin{abstract}
We present the synthesis of polymers by means of self-condensation of ethyl 3-aminophenyl acetate, using $\mathrm{HCl}$ as catalyst at high temperature and reduced pressure. This polymer was fractionated by successive precipitation from mixtures of methanol/diethylether of different polarity, yielding three polymeric fractions: Poly A, Poly B and Poly C. Likewise, under the same conditions, 3aminophenyl acetic acid yields only one polymeric fraction, Poly $\mathrm{D}$. These polymers were characterized by elemental analysis, IR and, in some cases, by ${ }^{1} \mathrm{H}-\mathrm{NMR}$ and X-Ray Photoelectron Spectroscopy (XPS). The obtained results show that polymers can be classified as hybrid materials, because in the backbone, they contain simultaneously the amide and imine groups and, at the end of the chain, they have amine and carboxylic acid functions. High solubility of some of these polymers in DMF or methanol has permitted the determination of viscosities and the preparation of films. Poly $B$ and Poly $C$ films exhibit amorphous morphology; and Poly D display spherullitic-type semi-crystallization pattern. The polymers can absorb solvents and they can swell up forming large-sized gels in DMF and methanol. Besides these polymers have high thermal stability that reaches a weight loss of $11.60 \%$ at $353^{\circ} \mathrm{C}$.
\end{abstract}

\section{Introduction}

The poly(imines), also called Schiff Base polymers, are conjugated aromatic polymers that actually are being studied as luminescent [1,2] and semiconductor materials [3] and also by their liquid-crystalline phase [4] or nonlinear optical properties $[5,6]$. Usually, these polymers are prepared by a condensation reaction between substituted aromatic dialdehydes and a phenylendiamines as monomers, Scheme 1a [7-11]. Another method for obtaining these types of polymers involves monomers as diketones (or diacetals) and phenylendiamines, yielding structures called ketanil polymers, Scheme $1 \mathrm{~b}[12,13]$. Poly(imines) are usually intractable materials, in other words, they are insoluble and infusible; however, they have a high thermal stability [8, 12, 14]. Substituted polyimines that contain alcoxo-, trifluoro methyl- or alkyl-groups, on the side chain, have been also reported [15-19]. 

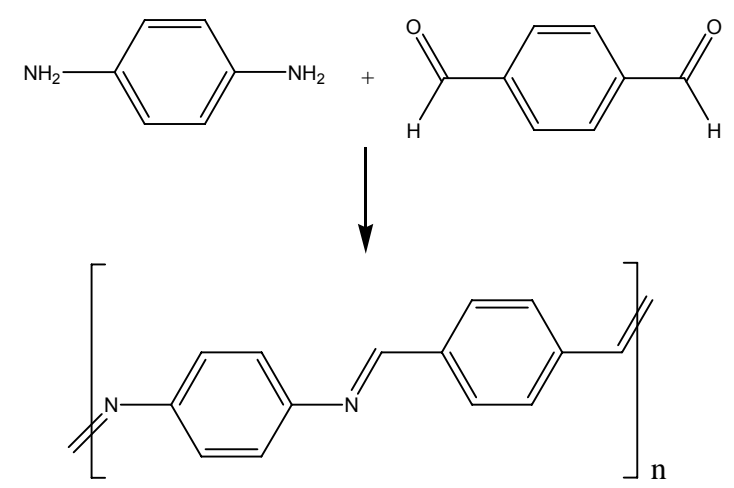

a

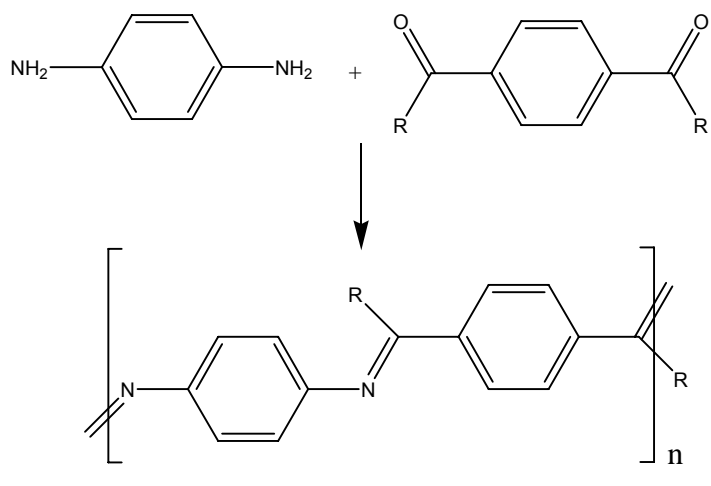

b

Scheme 1. A classical preparation of: a) Poly(imines) b) Poly(ketanil), $R=$ alkyl group.

In a previous paper, we have reported the synthesis and characterization of oligomers prepared by self-condensation of the monomers ethyl 3-aminophenyl acetate and 3-aminophenyl acetic acid [20]. Reactions were carried out at atmospheric pressure and high temperature, $220^{\circ} \mathrm{C}$, using $\mathrm{HCl}$ as catalyst. The obtained oligomers, with low intrinsic viscosity, $0.02-0.12 \mathrm{dL} / \mathrm{g}$, can be classified as hybrid materials, because in the backbone, they contain amide groups mainly and imine groups in minor proportion. Now, using the same monomers, we report the syntheses and characterization of hybrid materials of higher molecular size, changing the self-condensation condition. Spectroscopic, physical and chemical properties of them are discussed.

\section{Results and Discussion}

In a previous paper [20], ethyl 3-aminophenyl acetate and 3-aminophenyl acetic acid were oligomerized at high temperature, using $\mathrm{HCl}$ as catalyst. These reactions yielded products of low viscosity, $0.02-0.12 \mathrm{dL} / \mathrm{g}$, i.e. oligomers.

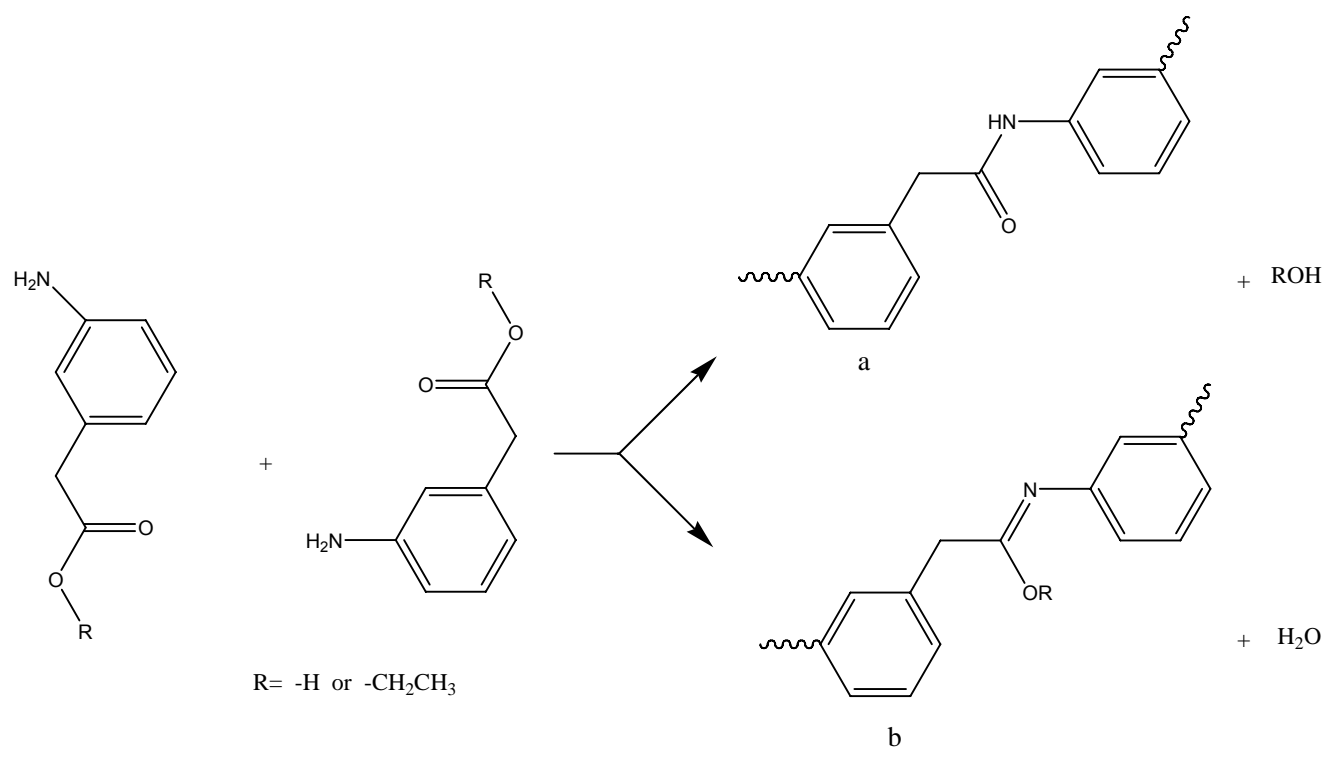

Scheme 2. Functional groups on the backbone in the previous oligomers reported. 
The functional groups of the backbone, amide and imine, were formed by random self-condensation reaction, which involves a substitution (Scheme 2a) or additionelimination (Scheme 2b) mechanism between the amino groups with the carbonyl derivative groups of ester or carboxylic acid, loosing ethanol or water molecules, respectively.

Contrarily, when the self-condensation is carried out under low pressure $(5 \mathrm{~mm} \mathrm{Hg})$ and high temperature $\left(210-220^{\circ} \mathrm{C}\right)$ the ethanol and water molecules are eliminated in gaseous phase, extending the propagation of the random reaction and, in this way, products of bigger molecular weight can be obtained. The reaction, that may be explained using the same Scheme 2, yields soluble materials in DMF and the partial solubility of 3-aminophenyl acetate-derivative in methanol allows separating three fractions (Poly A, Poly B, Poly C) from methanol or methanol/diethylether solutions. It was not possible to fraction Poly $D$ due to the low solubility in methanol. The products, polymers, show intrinsic viscosities in the 3.56-1.16 dL/g range (Table 1) while in the respective oligomers the values fall in the $0.02-0.12 \mathrm{dL} / \mathrm{g}$ range [20]. The intrinsic viscosities indicate that the synthesized polymers have a bigger length of chain with respect to the oligomers [20]. On the other hand, according to [ $\eta$ ] values (Table 1 ) the length of the chain decrease in the order Poly A > Poly B > Poly C Poly $D$. The relatively low value of $[\eta]$ found for Poly $D(1.16 \mathrm{dL} / \mathrm{g}$, Table 1) is according to the better leaving capability of $\mathrm{CH}_{3} \mathrm{CH}_{2} \mathrm{O}^{-}$group, compared to the $\mathrm{OH}^{-}$ group. The empirical formula (Table 1 ) was normalized considering eight $\mathrm{C}$-atoms in each repetitive unit in the backbone. However, these formulas contain greater oxygen quantity than the expected one, probably because the polymers can absorb water molecules from air. A small quantity of chloride ion demonstrates presence of catalyst residues, $\mathrm{HCl}$, because of the terminal amine, or because imine groups probably react with acid, yielding the respective cations neutralized by chloride anion. The presence of $\mathrm{N}^{+}$, as well as the greater oxygen quantity found in the empirical structure, were confirmed by the XPS studies (vide infra, Tabla 2)

Tab. 1. Elemental analysis, intrinsic viscosities and empirical formula found in polymers.

\begin{tabular}{|c|c|c|c|c|c|c|c|}
\hline Polymeric Samples & $\% \mathrm{C}$ & $\% \mathrm{H}$ & $\% \mathrm{~N}$ & $\% \mathrm{Cl}$ & $\% \mathrm{O}^{*}$ & [n] dL/g & Empirical Formula \\
\hline Poly A & 48.65 & 3.67 & 7.34 & 8.31 & 32.03 & 3.56 & $\mathrm{C}_{8.0} \mathrm{H}_{7.2} \mathrm{~N}_{1.0} \mathrm{O}_{4.0} \mathrm{Cl}_{0}$ \\
\hline Poly B & 40.16 & 3.85 & 5.95 & 14.90 & 35.14 & 2.02 & $\mathrm{C}_{8.0} \mathrm{H}_{9.1} \mathrm{~N}_{1.0} \mathrm{O}_{5.3} \mathrm{Cl}_{1 .}$ \\
\hline Poly C & 54.20 & 4.46 & 7.99 & 2.71 & 30.64 & 1.16 & $\begin{array}{c}\mathrm{C}_{8.0} \mathrm{H}_{7.8} \mathrm{~N}_{1.0} \mathrm{O}_{3.4} \mathrm{Cl}_{0 .} \\
.\end{array}$ \\
\hline Poly D & 65.99 & 4.38 & 10.41 & 5.30 & 13.92 & 1.16 & $\mathrm{C}_{8.0} \mathrm{H}_{6.3} \mathrm{~N}_{1.1} \mathrm{O}_{1.3} \mathrm{Cl}_{0 .}$ \\
\hline
\end{tabular}

${ }^{*}$ determined by difference.

The SEM micrographs corresponding to Poly B films (Figure 1a) and Poly C (Figure 1b) shows amorphous character without a determined semi-crystallization pattern. Contrarily, Poly D yields a spherulite semi-crystallization pattern (Figure 1c) that consist of an array of crystal fibrils, that have grown radially outward, from a central nucleus and with the fibrils branch growing like a tree. Usually this type of semicrystallization appears in polymers of low molecular weight [21]. Comparatively, Poly $\mathrm{D}$ appears as the polymer with minor molecular weight than the rest. Although Poly D 
and Poly $\mathrm{C}$ have similar viscosities (Table 1 ) a greater relative quantity of terminal carboxylic acid function in Poly $D$ may generate the additional semi-crystalline interactions with respect to Poly $\mathrm{C}$.

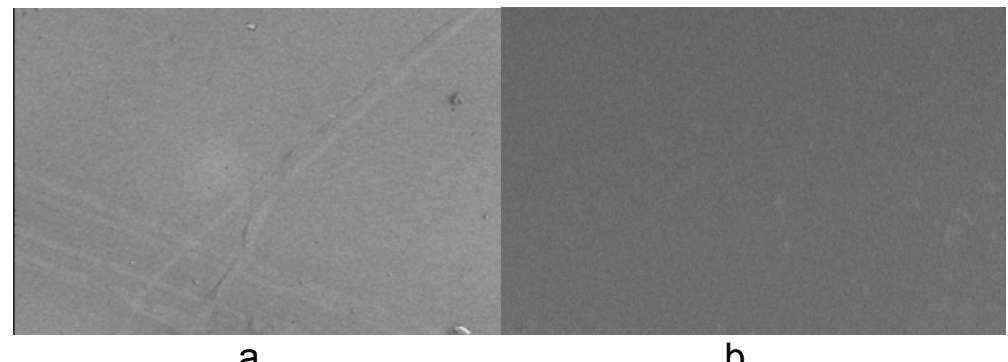

a

b

Fig. 1. SEM micrographs of: a) Poly B film, b) Poly C film.

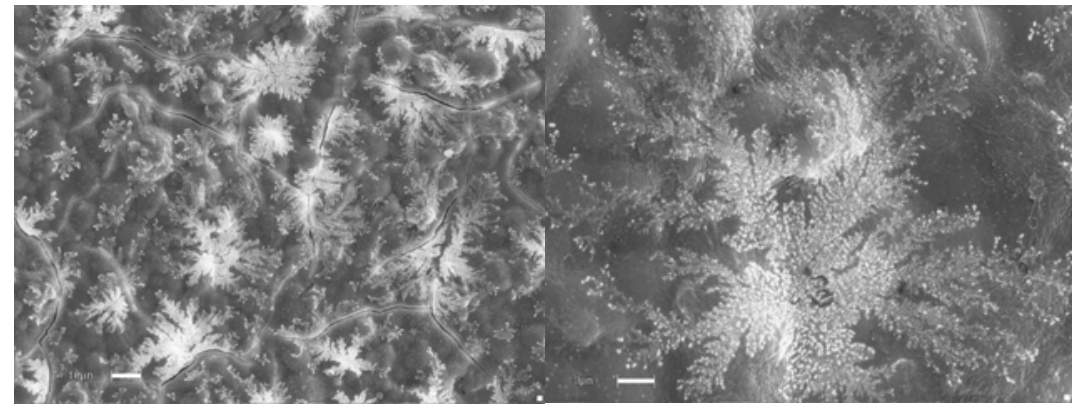

Fig. 2. SEM micrograph of Poly D film (right: enlarged micrograph).

Thermal stabilities of Poly A, Poly B and Poly C (Figure 3) present similar thermograms, up to $353{ }^{\circ} \mathrm{C}$, with a mass loss of $11.6 \%$. These results contrast with those found for the corresponding oligomers, whose stability comes up to $460{ }^{\circ} \mathrm{C}$ with a mass loss of $10 \%$. However, literature indicates that classical poly(imines) have the highest thermal stability coming up to $400{ }^{\circ} \mathrm{C}$ with a mass loss of no more than a $10 \%[12,14]$. This indicates that, probably, the synthesized polymers contain a minor quantity of imine groups in the backbone. Contrarily, using the same explanation, Poly D appears as the most stable polymer over $353^{\circ} \mathrm{C}$.

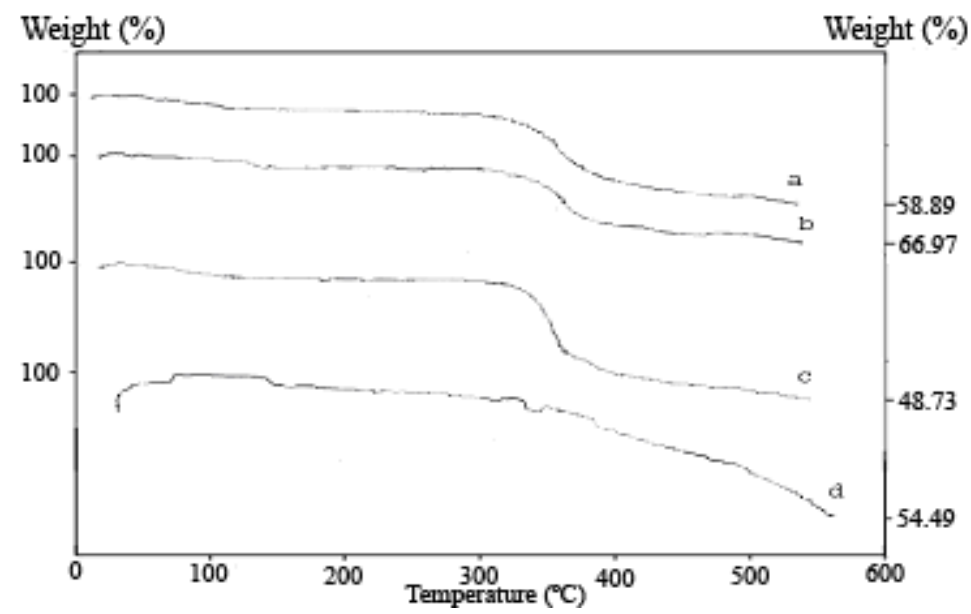

Fig. 3. Thermal stabilities of a) Poly A b) Poly B, c) Poly C d) Poly D. 
The IR spectra of polymers on $\mathrm{KBr}$ pellets are shown in Figure 4. Poly $\mathrm{A}$ exhibit broad absorptions corresponding to $\mathrm{v}(\mathrm{NH})$ and $\mathrm{v}(\mathrm{OH})$ centered at $3345 \mathrm{~cm}^{-1}, \mathrm{v}(\mathrm{C}=\mathrm{O})$ of amide at $1655 \mathrm{~cm}^{-1}, v(\mathrm{C}=\mathrm{C})$ aromatic ring at $1593 \mathrm{~cm}^{-1}, \delta(\mathrm{C}-\mathrm{H})$ aliphatic at 1393 $\mathrm{cm}^{-1}, \delta(\mathrm{C}-\mathrm{H})$ out of plane deformation pattern corresponding to 1,3-disubstituted aromatic ring at $775 \mathrm{~cm}^{-1}$ and $720 \mathrm{~cm}^{-1}$.

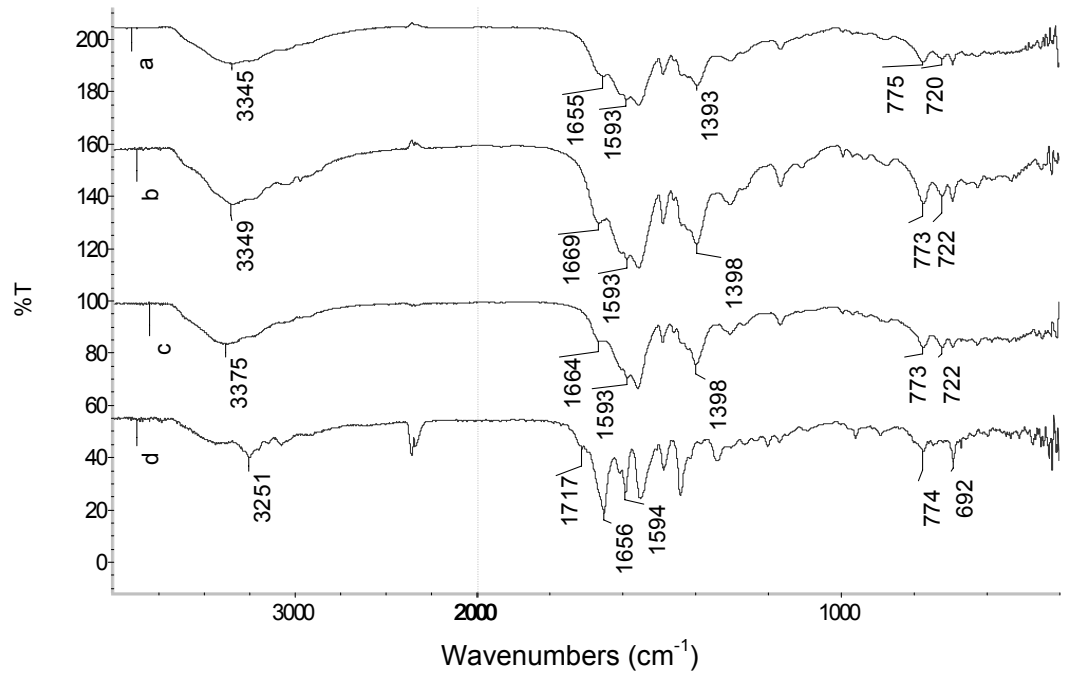

Fig. 4. IR spectra of a) Poly A, b) Poly B, c) Poly C and d) Poly D.

Similar IR absorptions bands may be found in Poly B and Poly C, indicating that the structures differ in the length of the chain. On the other hand, the IR spectrum of poly $\mathrm{D}$, display more sharp signals. The main absorption bands correspond to $\mathrm{v}(\mathrm{NH})$ and $\mathrm{v}(\mathrm{OH})$ over $3200 \mathrm{~cm}^{-1}, \mathrm{v}(\mathrm{C}=\mathrm{O})$ of carboxylic acid at the end of the chain at $1717 \mathrm{~cm}^{-1}$, $\mathrm{v}(\mathrm{C}=\mathrm{O})$ of amide at $1656 \mathrm{~cm}^{-1}, \mathrm{v}(\mathrm{C}=\mathrm{C})$ aromatic at $1594 \mathrm{~cm}^{-1}, \delta(\mathrm{C}-\mathrm{H})$ out of plane deformation pattern corresponding to 1,3-disubstituted aromatic ring at $774 \mathrm{~cm}^{-1}$ and $692 \mathrm{~cm}^{-1}$.

These polymers can absorb solvents and they can swell up forming large-sized gels in DMF and methanol. The IR spectra of the gels show hydrogen bridge interactions with the solvent. In fact, the IR spectrum of the gel obtained from Poly D in DMF (Figure 5a) exhibits clearly two absorption bands at $2112 \mathrm{~cm}^{-1}$ and $1256 \mathrm{~cm}^{-1}$, probably due to the interactions of the terminal amine and internal imine protons with the carbonyl groups of DMF. On the other hand, the IR spectrum of the gel of Poly D in methanol (Figure 5b) show that the carbonyl absorption, located at $1656 \mathrm{~cm}^{-1}$ on $\mathrm{KBr}$ disk, Figure $4 \mathrm{~d}$, is displaced toward a bigger frequency, $1685 \mathrm{~cm}^{-1}$ (Figure $5 \mathrm{~b}$ ) in methanol, indicating that there are interactions through hydrogen bridge between the electrons pairs of $\mathrm{N}$-amide with the HO-groups of methanol that reinforce the carbonyl union.

In DMSO- $\mathrm{d}_{6}$ only Poly $\mathrm{C}$ yields a suitable solution for obtaining the ${ }^{1} \mathrm{H}$ NMR spectrum (Figure 6). This polymer exhibits two resonances, at $1.10 \mathrm{ppm}$ and $4.75 \mathrm{ppm}$, corresponding to the $\mathrm{CH}_{3}$ - and $-\mathrm{CH}_{2}-$ protons of the ethyl group of the side chain, respectively. The methylene groups next to the functions amide and imine were observed at $3.10 \mathrm{ppm}$ and $3.20 \mathrm{ppm}$, respectively. A complicated multiplet, located in the 6.10-7.60 ppm range was assigned to the aromatic protons. Terminal $\mathrm{NH}_{2-}$ and the amide $\mathrm{NH}$ - protons were found at $4.95 \mathrm{ppm}$ and $10.10 \mathrm{ppm}$. Finally, a resonance at ca $10.28 \mathrm{ppm}$ was assigned to the terminal $\mathrm{OH}$ groups; indicate that the terminal ester groups have been hydrolyzed in the course of reaction. 


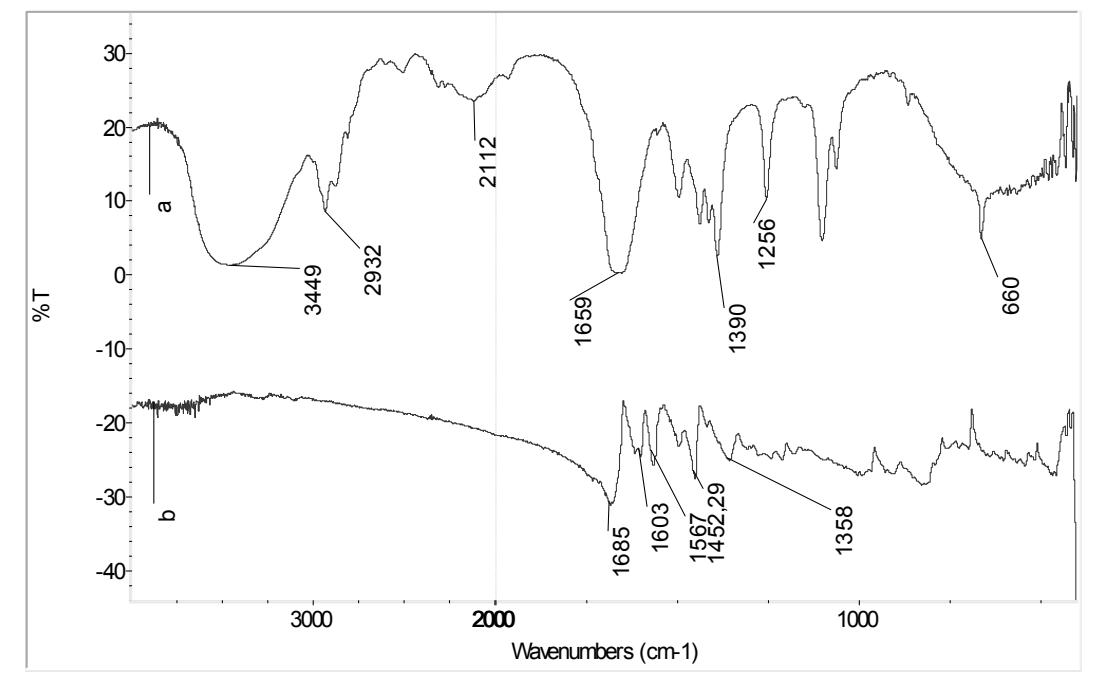

Fig. 5. FT-IR spectra of gels of Poly D prepared in a) DMF and b) methanol.

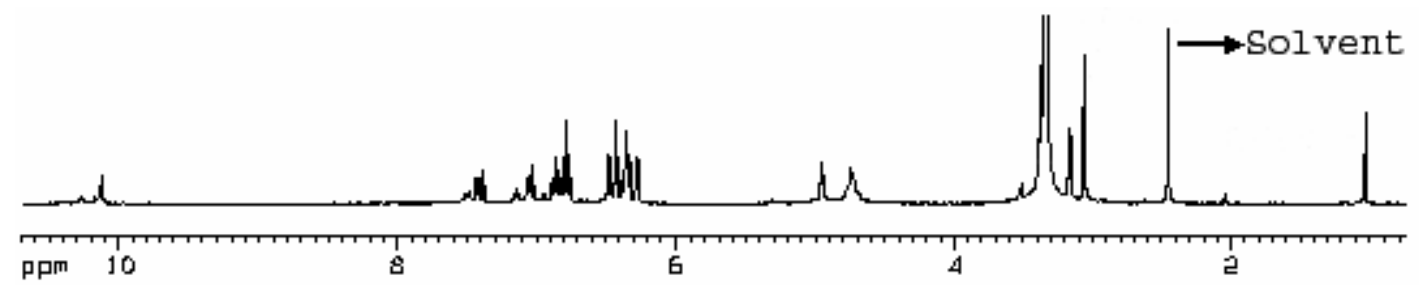

Fig. 6. ${ }^{1} \mathrm{H}-\mathrm{NMR}$ spectrum of Poly $\mathrm{C}$ registered in DMSO- $\mathrm{d}_{6}$.

Figures 7, 8 and 9 show the XPS spectrum of Poly A. This polymer does not have electric conductivity and then the carbon-carbon signal used as reference was displaced in $0.84 \mathrm{eV}$ by charge effect. The binding energies, Table 2, were corrected as is recommended in literature [22].

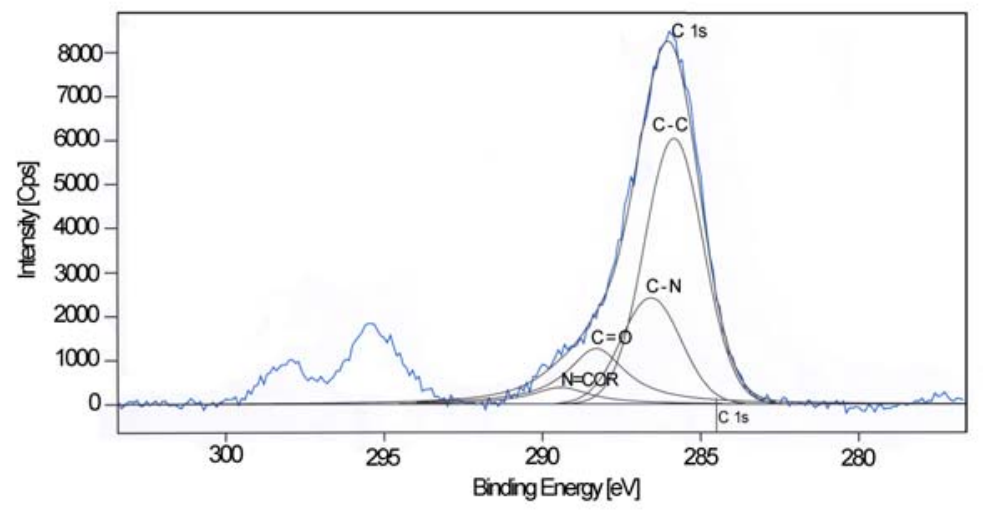

Fig. 7. Curve-fitting of $C_{1 s}$ peaks of Poly $A$.

The $\mathrm{C}_{1 \mathrm{~s}}$ signal, Figure 7, was decomposed in four peaks, Table 2. The first one at $285.0 \mathrm{eV}$, correspond to the carbon-carbon bond; the second one at $285.8 \mathrm{eV}$, to the $\mathrm{C}-\mathrm{N}$ of amide; the third one at $287.5 \mathrm{eV}$, to the $\mathrm{C}=\mathrm{O}$ of amide and the last at $288.6 \mathrm{eV}$ has been attributed to the $\mathrm{C}=\mathrm{N}$ of the imine union. On the other hand, the $\mathrm{N}_{1 \mathrm{~s}}$ signal 
(Figure 8) was decomposed in three peaks, Table 2. The first one at $399.2 \mathrm{eV}$ correspond to the imine bond; the second one at $400.0 \mathrm{eV}$ to the amine of amide, also present in the terminal amine, and the third one at $401.2 \mathrm{eV}$ to the charged nitrogen, indicating that there are some of protonated nitrogen, namely imine or terminal amine groups.

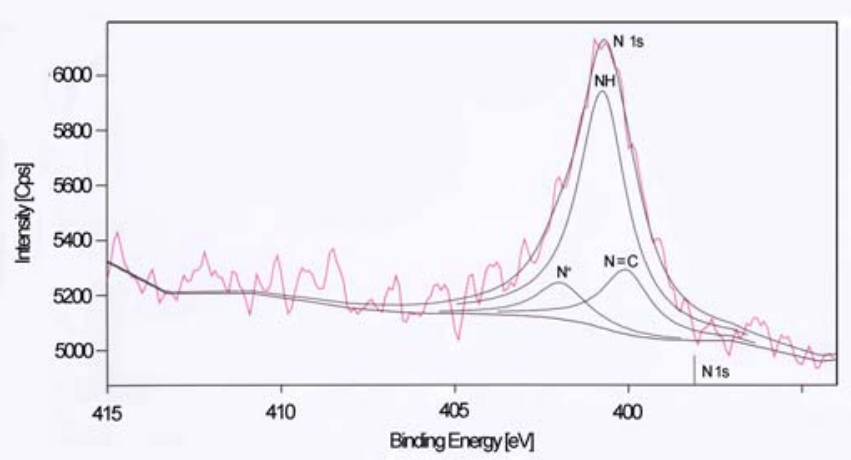

Fig. 8. Curve-fitting of $\mathrm{N}_{1 \mathrm{~s}}$ peak of Poly $A$.

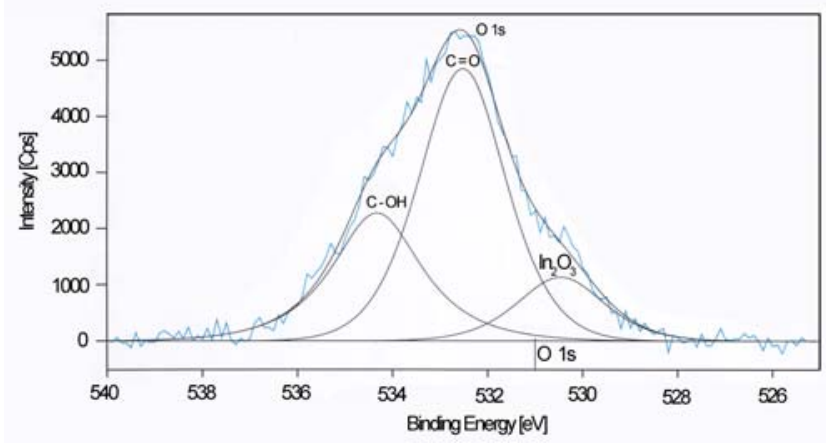

Fig. 9. Curve-fitting of $\mathrm{O}_{1 \mathrm{~s}}$ of Poly A.

Finally, the $\mathrm{O}_{1 \mathrm{~s}}$ signal (Figure 9) was decomposed in three peaks (Table 2) the most intense at $531.7 \mathrm{eV}$ is due to $\mathrm{C}=\mathrm{O}$ bond of amide; the second one at $533.5 \mathrm{eV}$ to the $\mathrm{C}-\mathrm{OH}$ of terminal carboxylic acid and the third one at $529.8 \mathrm{eV}$, is due to $\ln _{2} \mathrm{O}_{3}$ formed in the sheet surface. Also, Table 2 shows the binding energies and the relative atomic percentage of each union. The most relevant composition corresponds to $\mathrm{NH}$ amide $(70 \%)$ and imine $(20 \%)$ groups, where the ratio, 3.50 , indicates that internal backbone has predominantly the amide moiety.

Tab. 2. Analysis of corrected XPS of Poly A after decomposition of each signal.

\begin{tabular}{|c|c|c|c|c|c|c|c|c|c|c|}
\hline & \multicolumn{3}{|c|}{$\mathrm{C}_{1 \mathrm{~s}}$} & & \multicolumn{3}{|c|}{$\mathrm{N}_{1 \mathrm{~s}}$} & \multicolumn{3}{|c|}{$\mathrm{O}_{1 \mathrm{~s}}$} \\
\hline & C-C & $\begin{array}{c}\text { C-N } \\
\text { (amide) }\end{array}$ & $\begin{array}{c}\mathrm{C}=\mathrm{O} \\
\text { (amide) }\end{array}$ & $\begin{array}{c}\mathrm{N}=\mathrm{C}(\mathrm{OR}) \\
\text { (imine) }\end{array}$ & $\begin{array}{c}\mathrm{N}= \\
\text { (imine) }\end{array}$ & $\begin{array}{c}\mathrm{NH} \\
\text { (amide) }\end{array}$ & $\mathrm{N}+$ & $\mathrm{C}=\mathrm{O}$ & $\begin{array}{l}\mathrm{C}- \\
\mathrm{OH}\end{array}$ & $\begin{array}{c}\ln _{2} \mathrm{O} \\
3\end{array}$ \\
\hline $\begin{array}{l}\text { Binding } \\
\text { energies } \\
\text { (eV) }\end{array}$ & 285.0 & 285.8 & 287.5 & 288.6 & 399.2 & 400.0 & 401.2 & 531.7 & 533.5 & $\begin{array}{r}529 . \\
8\end{array}$ \\
\hline $\begin{array}{l}\% \text { atomic } \\
\text { relative }\end{array}$ & 57 & 23 & 15.5 & 4.6 & 20 & 70 & 10 & 57 & 30 & 13 \\
\hline $\begin{array}{l}\text { FWHM } \\
(\mathrm{eV})\end{array}$ & & 2.23 & & & & 1.7 & & & 2.24 & \\
\hline
\end{tabular}




\section{Conclusions}

We have obtained hybrid polymers from ethyl 3-aminophenyl acetate and 3aminophenyl acetic acid using a self-condensation polymerization reaction of each monomer at high temperature, low pressure and catalyzed by $\mathrm{HCl}$. In this way, it was possible to increase the intrinsic viscosity of the products, with respect to the same reaction carried out under atmospheric pressure. These hybrid materials contain simultaneously the amide and imine groups in backbone and amine and carboxylic acid as terminal functions. Besides, properties such as high thermal stability and high capacity to form large-sized gels were also found. These results are according to spectroscopic and XPS studies.

\section{Experimental}

\section{Physical measurements}

Elemental analysis, C, H, N, were obtained from an EA-1108, Fisons Elemental Analyzer and the total quantity of chloride from the ASTM standard method [23]. IR spectra were recorded on a Nicolet FT-IR Nexus spectrophotometer on $\mathrm{KBr}$ pellets. 1500 scans were registered for obtaining the IR spectra of gels on a $\mathrm{KBr}$ in cell for liquids, with the respective solvent, DMF or methanol, as blank. NMR spectrum was obtained from DMSO- $d_{6}$ solutions using TMS as internal reference on a $400 \mathrm{MHz}$ Bruker spectrophotometer. Thermogravimetric analysis, TGA, were registered under $\mathrm{N}_{2}$ atmosphere on a STA 625 Thermal Analyzer at $10^{\circ} \mathrm{C} / \mathrm{min}$. Intrinsic viscosity, [ ], were registered from DMF solution at $298 \mathrm{~K}$ on an Ostwald-type capillary, without kinetic energy correction and the [ $\eta$ ] values were generated using the SolomonGotessman equation [24]. The X-Ray Photoelectron Spectroscopy (XPS) was recorded on a Leybold LHS-12 spectrometer. The data were obtained with a magnesium source of radiation (1253.6 eV) operating at $10 \mathrm{kV}$ and $10 \mathrm{~mA}$, and the energy pass was set to $50 \mathrm{eV}$. Hight resolution scans with a good signal-to-noise ratio were obtained in the $\mathrm{C}_{1 \mathrm{~s}}, \mathrm{~N}_{1 \mathrm{~s}}$, and $\mathrm{O}_{1 \mathrm{~s}}$ regions of the spectrum. The powder of the polymeric sample was fixed to the substrate holder by pressing the polymer powder onto a sheet of indium. The decomposition of the XPS peaks into different components and the quantitative interpretation were made after the subtraction of the background using the Shirley method [25]. The curve-fitting programs allow the variation of parameters, such as the Gaussian/Lorentzian ratio, the Full-width at halfmaximum (FWHM), besides the position and the intensity of the contribution. These parameters were optimized by a curve-fitting program to obtain the best fit.

\section{Thermal polymerization of monomer}

Precursors, ethyl 3-aminophenyl acetate and 3-aminophenyl acetic acid, were prepared as reported in literature $[26,27]$. Both monomers were polymerized at high temperature and at low pressure using $37 \%$ aqueous $\mathrm{HCl}$ as catalyst. In a $10 \mathrm{ml}$ round-bottomed flask $0.97 \mathrm{~g}$ of ethyl 3-aminophenyl acetate and $0.098 \mathrm{~g}$ of HCl were added. The reaction mixture was connected to a vacuum system to attain $5 \mathrm{~mm} \mathrm{Hg}$ and heated on an oil-bath at $210-220^{\circ} \mathrm{C}$ for $1 \mathrm{~h}$. After cooling to room temperature the product was successively washed with chloroform, hexane, diethylether and acetone. Similar procedure may be used for polymerization of 3-aminophenyl acetic acid, using $1.23 \mathrm{~g}$ and $0.16 \mathrm{~g}$ of the precursor and catalyst, respectively. 


\section{Fractionation and purification of polymers}

Polymer obtained from ethyl 3-aminophenyl acetate was fractioned in two polymeric samples of lower intrinsic viscosity. This polymer was added in methanol $(20 \mathrm{ml})$ stirring for $10 \mathrm{~min}$, then, the insoluble fraction, Poly A, was filtered off by suction. Poly $B$ and Poly $C$ were successively filtered adding $10 \mathrm{ml}$ and a large excess $(100 \mathrm{ml})$ of diethylether over the soluble fraction, respectively. All fractions were vacuum dried at $60{ }^{\circ} \mathrm{C}$ for two days. Yields: Poly A: $0.20 \mathrm{~g}$; Poly B: $0.15 \mathrm{~g}$; Poly C: $0.08 \mathrm{~g}$.

On the other hand, the polymer obtained from 3-aminophenyl acetic acid was washed twice with methanol. After filtering, the polymer was dissolved in hot DMF and then precipitated adding an excess of diethylether. The solid, labeled as Poly D, was filtered off, washed with diethylether and vacuum dried at $80{ }^{\circ} \mathrm{C}$ for two days. Yield: $0.15 \mathrm{~g}$. It was not possible to fraction this polymer because it has high molecular weight.

\section{Preparations of gels and films}

Gels were prepared by adding an excess of DMF or methanol on Poly D and leaving the experiments at room temperature for two days. Films of Poly B, Poly C and Poly $\mathrm{D}$ were prepared by solvent evaporation from a solution of polymer in DMF at $80^{\circ} \mathrm{C}$ on a $2 \times 3 \mathrm{~cm}$ glass plate.

\section{Acknowledgements}

The authors thank to DID-UACH, Grants, S 2004-07, S 2006-20 for financial support for this work.

\section{References}

[1] Wang, X.; Ogino, K.; Tanaka, K.; Usui, H. Thin Solid Films 2003, 438/439, 75.

[2] Yang, Z.; Sokolik, I.; Karasz, F. E. Macromolecules 1993, 26, 1188.

[3] Lee, K. S.; Won, J. C.; Jung, J. C. Makromol Chem 1989, 190, 1547.

[4] Yang, H.; Natansohn, A. Polymer 1993, 34, 4135.

[5] Jenecke, S. A.; Yang, C.-Y.; Vanherzecle, H.; Meth, J. S. Chem Mat 1991, 3, 985

[6] Yang, C.-Y.; Jenecke, S. A. Chem Mat 1994, 6, 196.

[7] Adams, R.; Bullock, J.; Wilson, W. J. Am. Chem. Soc. 1923, 45, 521.

[8] Topchiev, A. V.; Korshak, V. V.; Popov , U. A.; Rosentein, L. D. J. Polymer Sci. 1963, C4, 1305.

[9] Stivala, S. S.; Sacco, G. R.; Reich, L. Polymer Letters 1964, 2, 943.

[10] D`Alelio, G. F.; Crivello, J. V.; Dehner, T. R.; Schoenig, R. K. J. Macromol. Sci 1967 A1(7), 1331.

[11] D`Alelio, G. F.; Strazik, W. F.; Feigl, D. M.; Schoenig, R. K. J. Macromol. Sci. Chem. 1968, A(2), 1457.

[12] D`Alelio, G. F.; Crivello, J. V.; Schoenig , R. K.; Huemmer, T. F. J. Macromol. Sci. 1967, A1, 1161.

[13] D`Alelio, G. F.; Kurosaki, T.; Ostdick, T. J. Macromol. Sci. Chem. 1968, A(2), 285.

[14] D`Alelio, G. F.; Crivello, J. V.; Schoenig,R. K.; Huemmer, T. F. J. Macromol. Sci. 1967, A1, 1321.

[15] Park, S-B; Kim, H.; Zin, W.-C.; Jung, J. C. Macromolecules 1993, 26, 1627.

[16] Morgan, P W.; Kwolek, S. L.; Pletcher T. C. Macromolecules 1987, 20, 729.

[17] Reinhardt, B. A.; Unroe, M. R. Polym. Prep. 1990, 31, 620. 
[18] Reinhardt, B. A.; Unroe M. R. Polymer. Commun. 1991, 32, 85.

[19] Bryant, R. G. Polym Prep 1992, 33, 182.

[20] Sánchez, C. O.; Bustos, C. J.; Alvarado, F. A.; Gatica, N.; Fernández, N.; Polymer Bulletin 2006, 57, 505.

[21] Wang, J-L.; Dong, C-M. Polymer 2006, 47, 3218.

[22] Briggs, D.; Seah, M. P. Practical Surface Analysis Vol. 1, Auger x-ray photoelectron Spectroscopy, $2^{\text {nd }}$ ed. ; Wiley : New York, 1990 ; P. 543.

[23] ASTM Method 1981, 30, 103.

[24] Solomon, O.; Gotessman, B. J Makromol Chem 1967, 104, 177.

[25] Shirley, D. A. Phys. Rev. B 1972, 5, 4709.

[26] Sánchez, C. O. J Appl Polym Sci 2003, 89, 1484.

[27] Sánchez, C. O.; Bustos, C. J.; Mac-leod Carey, D.; Gatica N. Polymer Bulletin 2005, 55, 71. 